\title{
Retrospective evaluation of the effect of carotid artery stenosis on cerebral oxygen saturation during off-pump coronary artery bypasses grafting in adult patients
}

S. Toyama ${ }^{* *}$, K. Matsuoka $^{2}$, Y. Tagaito ${ }^{2}$ and M. Shimoyama ${ }^{2,3}$

\begin{abstract}
Background: It is unknown whether cerebral oxygenation in patients with carotid artery stenosis (CAS) undergoing off-pump coronary artery bypass grafting (CABG) differs from that in patients without CAS. Thus, the effect of the presence of CAS $\geq 50 \%$ on cerebral oxygenation during off-pump CABG in adult patients was evaluated retrospectively.

Methods: Eleven patients with CAS $\geq 50 \%$ and 14 patients without CAS $\geq 50 \%$ were enrolled. Regional cerebral tissue oxygen saturation $\left(\mathrm{rSO}_{2}\right)$ was quantified using near-infrared spectroscopy. Mean arterial pressure, cardiac index, central venous pressure (CVP), and $\mathrm{rSO}_{2}$ at specific points were collected, and significant changes in each parameter were detected using repeated analysis of variance. Mean $\mathrm{rSO}_{2}$ and minimum $\mathrm{rSO}_{2}$ during anastomosis were analyzed by one-way analysis of variance. Multiple logistic regression analysis was used to estimate the odds ratio (OR) with $95 \%$ confidence interval (Cl) for cerebral desaturation (a decrease in $\mathrm{rSO}_{2} \geq 10 \%$ from preoperative value).

Results: Two patients with CAS $\geq 50 \%$ who received complete carotid artery stenting preoperatively were excluded from the analyses. In both patients with and without CAS, a decrease in $\mathrm{rSO}_{2}$ and cardiac index and an increase in CVP were observed during anastomosis. Mean (SD) maximum decrease in $\mathrm{rSO}_{2}$ from preoperative value was 9.2 (12.7) \% on the left side and 8.1 (11.7) \% on the right side in patients with CAS $\geq 50 \%$, and 13.5 (11.3) \% on the left side and 16.1 (9.8) \% on the right side in patients without CAS $\geq 50 \%$ ( $p=0.316)$. Neurological complications were not identified in both patients with and without CAS $\geq 50 \%$. In multiple logistic regression analysis, CAS $\geq 50 \%$ was not associated with an increased risk of cerebral desaturation (OR 0.160, $95 \% \mathrm{Cl} 0.036-0.707, p=0.016)$, and $\mathrm{rSO}_{2}$ decreased with decreasing cardiac index $<2.0 \mathrm{l} / \mathrm{min} / \mathrm{m}^{2}$ (OR 3.287, $\left.95 \% \mathrm{Cl} 2.218-5.076, p<0.001\right)$.

Conclusions: CAS $\geq 50 \%$ was not an independent risk factor of cerebral desaturation during off-pump CABG. Our results suggest that maintaining cardiac output can prevent a decrease in cerebral oxygenation in both patients with and without $C A S \geq 50 \%$.
\end{abstract}

Keywords: Carotid artery stenosis, Cerebral tissue oxygen saturation, Coronary artery bypass grafting, Near-infrared spectroscopy

\footnotetext{
* Correspondence: s-toyama@suite.plala.or.jp

${ }^{1}$ Department of Anesthesiology, Medical Hospital of Tokyo Medical and

Dental University, 1-5-45 Yushima, Bunkyo-Ku, Tokyo 113-8519, Japan

Full list of author information is available at the end of the article
} 


\section{Background}

Stroke following on-pump coronary artery bypass grafting $(\mathrm{CABG})$ is a major source of morbidity and mortality [1]. Although the etiology of such stroke is multifactorial, the use of cardiopulmonary bypass (CPB) is a major contributor for brain injuries [2-4]. Hence, off-pump CABG is expected to reduce perioperative strokes compared with on-pump CABG $[5,6]$. However, perioperative factors unrelated to $\mathrm{CPB}$, such as advanced age, female sex, low left ventricular ejection fraction (LVEF), diabetes mellitus, chronic kidney disease, vascular disease and nonelective surgery, are demonstrated to be associated with stroke following CABG [7]. Thus, the superiority of off-pump CABG to on-pump CABG for prevention of perioperative stroke is controversial [8-13].

Four to $17 \%$ of patients undergoing CABG have carotid artery stenosis $(\mathrm{CAS}) \geq 50 \%[14,15]$, and concomitant CAS is associated with an increased risk of stroke following on-pump CABG [16-18]. Since cerebral hemodynamics is impaired depending on the degree of the stenosis [19], CAS can provoke cerebral oxygen supply-demand mismatch when hemodynamic impairment occurs during surgery. However, the pathophysiological mechanism of most postoperative ischemic strokes in patients with CAS undergoing on-pump CABG is thought to be microemboli from ascending aorta and/or carotid artery, or cardioembolism rather than hypoperfusion to cause cerebral oxygen supply-demand mismatch $[17,20]$. Meanwhile, in general, hemodynamic depression due to moving the heart from its natural position during anastomosis can lead to a decrease in cerebral oxygenation more frequently during off-pump CABG than on-pump CABG [21]. Thus, CAS is likely to be associated with an increased risk of cerebral oxygen supply-demand mismatch to cause cerebral ischemia during off-pump CABG. However, little information is available for the effect of the presence of CAS on cerebral oxygenation in patients undergoing off-pump CABG.

Near-infrared spectroscopy (NIRS) is a non-invasive measure that provides continuous monitoring of regional cerebral tissue oxygen saturation $\left(\mathrm{rSO}_{2}\right)$, and $\mathrm{rSO}_{2}$ values reflect hemoglobin saturation in a mixture of arteries, capillaries, and veins [22]. Although most NIRS devices assume that the hemoglobin content of the cerebral cortex is distributed $75 \%$ in the venous and $25 \%$ in the arterial district, a previously reported study shows that there are considerable biological variations in individual cerebral arterial-venous ratios between patients, suggesting that absolute $\mathrm{rSO}_{2}$ values present interindividual variability [23]. However, using NIRS as a trend monitor can minimize the inter-individual variables, and NIRS has been demonstrated to be a clinically useful monitor of cerebral oxygenation in various settings [24-30]. Thus, we retrospectively examined the effect of CAS $\geq 50 \%$ on cerebral oxygenation during off-pump CABG in adult patients by assessing $\mathrm{rSO}_{2}$ values derived from NIRS.

\section{Methods \\ Patients}

Following the Institutional Ethics Committee approval of Teikyo University, Tokyo, Japan (reference number 13-252), we retrospectively analyzed data from patients who underwent off-pump CABG at Teikyo University Chiba Medical Center (Chiba, Japan) from April 2009 to March 2014. All patients received carotid duplex sonography and brain computed tomography $(\mathrm{CT})$ preoperatively, and the severity of CAS was assessed using area stenosis as stenosis (stenosis $\geq 50 \%$ ) or none (stenosis < $50 \%)$. Patients who received mechanical ventilation under intubation preoperatively and did not receive pulmonary artery catheterization and $\mathrm{rSO}_{2}$ monitoring during surgery were excluded from the present study. All operations were performed by the same cardiovascular surgical team. When preoperative thoracic enhanced CT and intraoperative transaortic echocardiography revealed calcifications in the ascending aorta, an aortic no-touch technique, in which only arterial grafts without surgical manipulation of the ascending aorta were used, or great saphenous vein graft anastomosis to the ascending aorta using the aortic proximal anastomotic device was performed.

\section{Anesthetic technique}

On the morning of surgery, patients were allowed to take their routine medication, except for angiotensin-converting enzyme inhibitors and angiotensin-II receptor blockers. Standard monitoring with electrocardiography, pulse oximetry, end-tidal carbon dioxide $\left(\mathrm{ETCO}_{2}\right)$, bispectral index (BIS), invasive arterial pressure measurement and rectal temperature measurement was performed. Arterial pressure was recorded continuously via the right radial artery catheter which was inserted before induction of anesthesia. Cerebral oxygenation was monitored by measuring $\mathrm{rSO}_{2}$ values derived from an INVOS 5100C cerebral oximeter (INVOS, Covidien, Mansfield, MA). Two disposable NIRS sensors were applied on each side of the forehead for continuous monitoring of $\mathrm{rSO}_{2}$ of the corresponding brain hemisphere. Anesthesia was induced with a continuous infusion of remifentanil $(0.3-0.5 \mu \mathrm{g} / \mathrm{kg} / \mathrm{min})$ and target controlled infusion of propofol $(2 \mu \mathrm{g} / \mathrm{ml})$, and a bolus of rocuronium $(1 \mathrm{mg} / \mathrm{kg})$. The lungs were ventilated mechanically with oxygen enriched air (fractional inspired oxygen of 0.6) adjusted to keep $\mathrm{ETCO}_{2}$ between 35 and $40 \mathrm{mmHg}$. The remifentanil infusion was titrated in a range of $0.2-0.5 \mu \mathrm{g} / \mathrm{kg} / \mathrm{min}$ to the patients' clinical requirement as judged by the anesthesiologist present. The propofol infusion was titrated to keep BIS level between 40 and 50. After tracheal intubation, a transesophageal echocardiography probe was placed, and pulmonary artery 
catheter was inserted via the right internal jugular vein. Central venous pressure (CVP), pulmonary artery pressure, cardiac index, and mixed venous blood oxygen saturation $\left(\mathrm{SvO}_{2}\right)$ were recorded continuously. Cardiac output was measured by thermodilution technique with a pulmonary artery catheter, and the cardiac index was calculated.

Crystalloid was infused starting before the induction of anesthesia until the completion of surgery. An initial heparin dose of $300 \mathrm{IU} / \mathrm{kg}$ was administered after pericardiotomy. Protamine $1.5 \mathrm{mg} / \mathrm{kg}$ was administered after anastomosis. When hemodynamic status was unstable (cardiac index $<2.0 \mathrm{l} / \mathrm{min} / \mathrm{m}^{2}$ and/or mean arterial pressure $(\mathrm{MAP})<60 \mathrm{mmHg}$ ) despite optimization of the circulating volume, dopamine was administered to increase CI above $2.01 \mathrm{~min} / \mathrm{m}^{2}$, and phenylephrine or norepinephrine was administered to increase MAP above $60 \mathrm{mmHg}$. All patients received a continuous infusion of nicorandil $(2 \mathrm{mg} / \mathrm{hr})$ throughout surgery. Blood transfusion was performed to maintain hemoglobin between 9 and $10 \mathrm{~g} / \mathrm{dl}$. Rectal temperature was kept between 36 and $37{ }^{\circ} \mathrm{C}$.

After anastomosis, fentanyl was given, and remifentanil was discontinued prior to the completion of surgery. Propofol administration was continued until postoperative tracheal extubation in the intensive care unit.

\section{Perioperative data collection}

Baseline $\mathrm{rSO}_{2}$ values and hemodynamic data (heart rate and MAP) were obtained before induction of anesthesia while patients were breathing under room air. Values of MAP, cardiac index, CVP, and $\mathrm{rSO}_{2}$ were continuously measured and simultaneously recorded at the same time points (every $5 \mathrm{~min}$ ) until the completion of surgery. Since the duration of anesthesia varied with cases due to the differences of the number of anastomosis, the time course comparison of these data between the two groups was performed at specific points during surgery: at skin incision, at heparin administration, at the beginning of grafting the left anterior descending coronary artery (LAD), at the beginning of grafting the left circumflex coronary artery (LCX), at the beginning of grafting the right coronary artery (RCA), at protamine administration, and at chest closure. Although an absolute $\mathrm{rSO}_{2}$ value for cerebral ischemia prediction cannot be defined, a decrease in $\mathrm{rSO}_{2} \geq 10 \%$ from baseline value indicates cerebral desaturation associated with cerebral dysfunction [22], and a decrease in $\mathrm{rSO}_{2} \geq 20 \%$ from baseline value indicates a critical reduction in cerebral oxygenation and perfusion $[25,27,28]$. Thus, the $\mathrm{rSO}_{2}$ values were also normalized by expressing them as a percentage change from baseline value.

Postoperative complications including major adverse cardiovascular events [31], neurological complications, duration of mechanical ventilation, and early postoperative death ( $<30$ days) were compared between patients with and without CAS. Neurological complication was defined as focal neurologic deficit persisting $\geq 24 \mathrm{~h}$ and confirmed by brain CT or magnetic resonance imaging (MRI).

\section{Statistical analysis}

We did not have preliminary data and similar previously reported studies to perform a power analysis. The sample size of a paired $t$-test was indicated to be $n=10(\alpha=0.05$, $\beta=0.20)$ to reveal a significant decrease in $\mathrm{rSO}_{2}$ value from preoperative value during surgery in patients with CAS, assuming that mean (SD) relative change between minimum and preoperative $\mathrm{rSO}_{2}$ was 10 (10) \%, which was based on a previously reported study showing that the decrease in $\mathrm{rSO}_{2}$ from preoperative value of 5-14 \% was observed during carotid cross-clamping in patients undergoing carotid endarterectomy with general anesthesia and ventilation adjusted to fractional inspired oxygen of 0.3-1.0 [32]. Patient characteristics and perioperative data were analyzed by unpaired Student's $t$-test, MannWhitney $U$-test or Fischer's exact probability test, one-way analysis of variance (ANOVA) with the Dunn post hoc test, as appropriate. Spearman's rank correlation coefficient $(r)$ was calculated to examine the relationships among preoperative patient characteristics (the degree of CAS or hemodynamic data (preoperative LVEF and baseline MAP) and $\mathrm{rSO}_{2}$ value. Hemodynamic data (MAP, cardiac index, and $\mathrm{CVP}$ ) and $\mathrm{rSO}_{2}$ at specific points during surgery in patients with and without CAS were analyzed by twoway repeated ANOVA with the Bonferroni post hoc test. In two-way repeated ANOVA, missing data were imputed using an expectation-maximization algorithm. In patients with $\mathrm{CAS}$ and without $\mathrm{CAS}$, mean $\mathrm{rSO}_{2}$ value, minimum $\mathrm{rSO}_{2}$ value, and the duration of a decrease in $\mathrm{rSO}_{2} \geq 10 \%$ and $\geq 20 \%$ from baseline value were analyzed by one-way ANOVA with the Dunn post hoc test. Multiple logistic regression analysis was used to estimate the odds ratio (OR) with $95 \%$ confidence interval $(\mathrm{CI})$ for cerebral desaturation (a decrease in $\mathrm{rSO}_{2} \geq 10 \%$ from baseline value) during anastomosis, with independent factors of $\mathrm{MAP}<60 \mathrm{mmHg}$, cardiac index $<2.0 \mathrm{l} / \mathrm{min} / \mathrm{m}^{2}$, CVP $>10 \mathrm{mmHg}$, CAS, CAS side of the forehead, and bilateral CAS. The ORs for cerebral desaturation were adjusted for every $1 \mu \mathrm{g} / \mathrm{kg} / \mathrm{min}$ increase in dopamine and every $0.01 \mu \mathrm{g} / \mathrm{kg} / \mathrm{min}$ increase in noradrenaline. Statistical significant was defined as $p<0.05$. The SigmaPlot statistical software package for Windows (version 11.2, Systat, Sa Jose, CA, USA) was used for statistical analysis.

\section{Results}

Figure 1 shows the flow diagram for the study. Thirty three patients were enrolled in the present study, and 8 subjects were excluded from final analysis because of the 


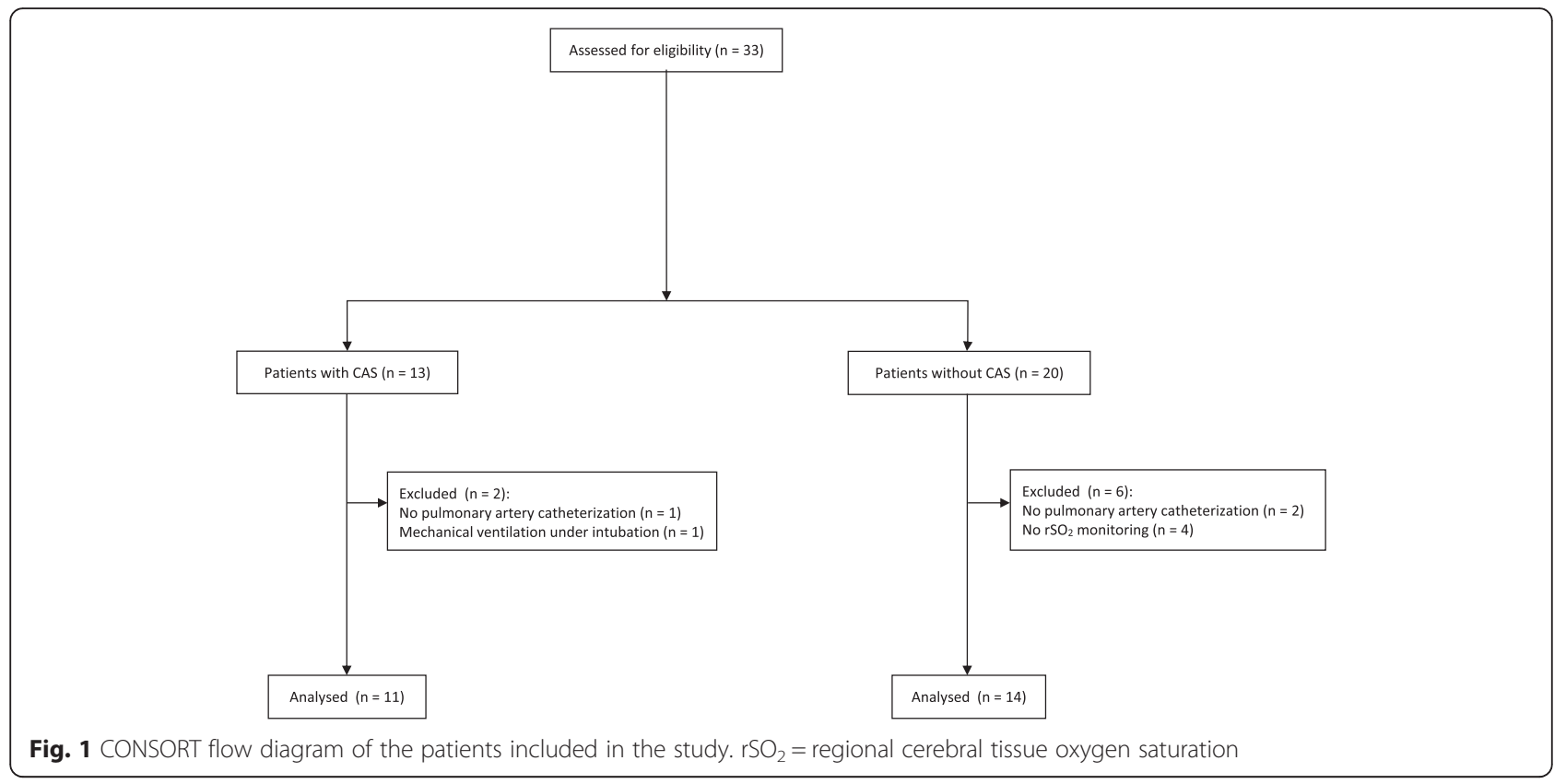

following factors: mechanical ventilation under midazolam administration (1 patient with CAS); no use of pulmonary artery catheterization (1 patient with CAS and 2 patients without CAS); no use of NIRS (4 patients without CAS). As a result, data analysis was performed on 25 patients (11 patients with CAS and 14 patients without CAS).

The demographic data in patients with CAS are presented in Table 1. Four patients had a unilateral high-grade $(\geq 70 \%)$ CAS, 1 patient had a unilateral moderate-grade $(\geq 50 \%)$ CAS with a contralateral occlusion, 2 patients had bilateral high-grade CAS, 2 patients had a unilateral high-grade CAS with a contralateral moderate-grade CAS, and 2 patients had bilateral moderate-grade CAS. In 3 of 9 patients with high-grade CAS, preoperative single photon emission computed tomography (SPECT) with acetazolamide stress was performed, but 6 other patients with high-grade CAS received CABG without preoperative SPECT with acetazolamide stress since the symptom of angina pectoris was uncontrollable by medical therapy. Three patients received carotid artery stenting prior to CABG. However, carotid artery stenting was unsuccessful in 1 patient. Thus, 2 patients with CAS who received complete carotid artery stenting preoperatively were excluded from the analyses.

The demographic and preoperative clinical findings of the study patients are shown in Table 2 . There were no significant differences between patients with and without CAS except for a history of cerebral infarction and/or transient ischemic attack (TIA) (9/9 [100.0 \%] and 2/14 [14.3\%], respectively, $p<0.001$ ). In patients with CAS, baseline $\mathrm{rSO}_{2}$ did not correlate with the degree of CAS $(r=-0.376, p=0.120)$ but correlated with both preoperative
LVEF $(r=0.509, p=0.0306)$ and baseline MAP $(r=0.572$, $p=0.0129)$. Meanwhile, in patients without CAS, baseline $\mathrm{rSO}_{2}$ correlated with neither preoperative LVEF $(r=0.153$, $p=0.433)$ nor baseline MAP $(r=0.275, p=0.154)$.

Surgical-related data and postoperative outcomes are presented in Table 3. Aortic not-touch technique was used more frequently in patients with CAS than those without CAS (4/9 [44.4\%] and 0/14 [0.0\%], respectively, $p=0.014$ ), but the frequency of the use of aortic notouch technique or aortic proximal anastomotic device was not different between patients with CAS and those without CAS (5/9 [55.6 \%] and 2/14 [14.3\%], respectively, $p=0.066$ ). Postoperative morbidity and mortality did not differ between patients with and without CAS, and neurological complications were not identified in both patients with and without CAS.

Figure 2 shows absolute $\mathrm{rSO}_{2}$ values or relative changes in $\mathrm{rSO}_{2}$ from baseline value at specific points during surgery in the study patients. Two-way repeated ANOVA revealed a significant within-subjects effect in both an absolute $\mathrm{rSO}_{2}$ value and a relative change in $\mathrm{rSO}_{2}$ from baseline value $(p<0.001$ and $p<0.001$, respectively). An absolute $\mathrm{rSO}_{2}$ value did not differ between patients with and without CAS $(p=0.805)$, but a relative changes in $\mathrm{rSO}_{2}$ from baseline value was smaller in patients with CAS than patients without CAS ( $p=0.048)$.

Table 4 shows $\mathrm{rSO}_{2}$ values during anastomosis in patients with CAS. The degree of CAS correlated with neither mean relative change in $\mathrm{rSO}_{2}$ from baseline value $(r=0.327, p=0.181)$ nor relative change in minimum $\mathrm{rSO}_{2}$ from baseline value $(r=0.424, p=0.0774)$. Table 5 shows $\mathrm{rSO}_{2}$ values during anastomosis in the study 
Table 1 Demographic information and baseline regional cerebral tissue oxygen saturation $\left(\mathrm{rSO}_{2}\right)$ in patients with carotid artery stenosis (CAS)

\begin{tabular}{|c|c|c|c|c|c|c|c|}
\hline Case & $\begin{array}{l}\text { Age } \\
\text { (yr) }\end{array}$ & $\begin{array}{l}\text { CAS } \\
\text { (Left/Right) (\%) }\end{array}$ & $\begin{array}{l}\text { Preoperative } \\
\text { SPECT }\end{array}$ & $\begin{array}{l}\text { Preoperative } \\
\text { stenting }\end{array}$ & $\begin{array}{l}\text { Baseline } \mathrm{rSO}_{2} \\
\text { (Left/Right) (\%) }\end{array}$ & Preoperative LVEF (\%) & $\begin{array}{l}\text { Baseline MAP } \\
(\mathrm{mmHg})\end{array}$ \\
\hline 1 & 50 & $0 / 80$ & Yes & Yes & $72 / 72$ & 61 & 117 \\
\hline 2 & 50 & $75 / 50$ & Yes & No & $52 / 51$ & 52 & 77 \\
\hline 3 & 77 & $50 / 50$ & No & No & $71 / 71$ & 64 & 113 \\
\hline 4 & 80 & $50 / 100$ & Yes & Incomplete & $56 / 53$ & 58 & 103 \\
\hline 5 & 68 & $50 / 50$ & No & No & $65 / 72$ & 41 & 97 \\
\hline 6 & 45 & $0 / 80$ & No & Yes & $59 / 54$ & 20 & 100 \\
\hline 7 & 52 & $75 / 70$ & No & No & $48 / 50$ & 22 & 67 \\
\hline 8 & 68 & $88 / 50$ & No & No & $70 / 66$ & 58 & 95 \\
\hline 9 & 78 & $70 / 70$ & No & No & $61 / 51$ & 42 & 82 \\
\hline 10 & 65 & $90 / 0$ & No & No & $52 / 57$ & 60 & 93 \\
\hline 11 & 71 & $80 / 0$ & No & No & $66 / 70$ & 67 & 75 \\
\hline
\end{tabular}

LVEF left ventricular ejection fraction, SPECT single photon emission computed tomography with acetazolamide stress, MAP mean arterial pressure

patients. Mean (SD) maximum decrease in $\mathrm{rSO}_{2}$ from preoperative value was 9.2 (12.7) \% on the left side and 8.1 (11.7) \% on the right side in patients with CAS, and 13.5 (11.3) \% on the left side and 16.1 (9.8) \% on the right side in patients without CAS $(p=0.316)$. The duration of a decrease in $\mathrm{rSO}_{2} \geq 10 \%$ and $\geq 20 \%$ from baseline value during anastomosis did not differ between patients with and without CAS $(p=0.479$ and $p=0.394$, respectively). The incidence of a decrease in $\mathrm{rSO}_{2} \geq 20 \%$ from baseline value during anastomosis was identified on both the sides of the forehead in one patient with CAS $(11.1 \%)$ and on the 5 left and 3 right sides of the

Table 2 Preoperative demographic data in patients with and without carotid artery stenosis (CAS)

\begin{tabular}{|c|c|c|c|}
\hline & Patients with CAS $(n=9)$ & Patients without CAS $(n=14)$ & $P$-value \\
\hline Age (yr) & $67[11]$ & $69[7]$ & 0.797 \\
\hline Gender (Male/Female) & $8 / 1$ & $9 / 5$ & 0.340 \\
\hline Body mass index $\left(\mathrm{kg} / \mathrm{m}^{2}\right)$ & $22[2]$ & $23[4]$ & 0.092 \\
\hline \multicolumn{4}{|l|}{ Preoperative complications ( $\mathrm{n}$ ) } \\
\hline Cerebral infarction and/or TIA & 9 [100.0\%] & 2 [14.3\%] & $<0.001$ \\
\hline Hypertension & 7 [77.8\%] & 12 [85.7\%] & 1.000 \\
\hline Diabetes mellitus & 7 [77.8\%] & 8 [57.1\%] & 0.659 \\
\hline Hyperlipidemia & 2 [22.2\%] & 3 [21.4\%] & 1.000 \\
\hline Chronic kidney disease on hemodialysis & 2 [22.2\%] & 3 [21.4\%] & 1.000 \\
\hline Congestive heart failure & 2 [22.2\%] & $0[0.0 \%]$ & 0.142 \\
\hline Atrial fibrillation & $0[0.0 \%]$ & $0[0.0 \%]$ & - \\
\hline \multicolumn{4}{|l|}{ Preoperative cardiac evaluation } \\
\hline Left ventricular ejection fraction (\%) & $58[22-67]$ & $57[31-74]$ & 0.387 \\
\hline Mitral regurgitation (grade*) & $0[0-3]$ & $0[0-3]$ & 0.607 \\
\hline Aortic regurgitation $\left(\right.$ grade* ${ }^{*}$ & $0[0-2]$ & $0[0-2]$ & 0.823 \\
\hline \multicolumn{4}{|l|}{ Preoperative hemodynamic data } \\
\hline HR (beats/min) & $76[9]$ & $70[11]$ & 0.181 \\
\hline MAP $(\mathrm{mmHg})$ & $89[15]$ & $96[15]$ & 0.293 \\
\hline Preoperative $\mathrm{rSO}_{2}$ (Left/Right) (\%) & $60[8] / 60[9]$ & $63[10] / 65[9]$ & 0.422 \\
\hline Preoperative hemoglobin ( $\mathrm{g} / \mathrm{dl}$ ) & $11.0[0.8]$ & $10.6[1.4]$ & 0.488 \\
\hline
\end{tabular}

Data are mean [SD], number, number [proportion] or median [range]

TIA transient ischemic attack, $\mathrm{HR}$ heart rate, MAP mean arterial pressure, $r \mathrm{SO}_{2}$ regional cerebral tissue oxygen saturation

*Grade of regurgitation: $0=$ none, $1=$ trivial, $2=$ mild, $3=$ moderate, $4=$ severe 
Table 3 Intraopeative and postoperative clinical data in patients with and without carotid artery stenosis (CAS)

\begin{tabular}{|c|c|c|c|}
\hline & Patients with CAS $(n=9)$ & Patients without CAS $(n=14)$ & $P$-value \\
\hline \multicolumn{4}{|l|}{ Surgical-related data } \\
\hline Anesthesia time (min) & 466 [119] & $425[67]$ & 0.301 \\
\hline Operation time (min) & $347[89]$ & $335[64]$ & 0.707 \\
\hline Duration of anastomosis (min) & $170[45]$ & $186[52]$ & 0.455 \\
\hline Number of anastomosis ( $n$ ) & $3[1-5]$ & $4[2-4]$ & 0.341 \\
\hline Aortic no-touch technique (n) & 4 [44.4\%] & $0[0.0 \%]$ & 0.019 \\
\hline Aortic proximal anastomosis device (n) & 1 [11.1\%] & $2[14.3 \%]$ & 1.000 \\
\hline Packed red blood cell transfusion (U) & $0[0-6]$ & $2[0-6]$ & 0.224 \\
\hline Cumulative dose of phenylephrine $(\mu \mathrm{g})$ & $400[0-650]$ & $150[0-800]$ & 0.948 \\
\hline Maximum dose of dopamine $(\mu \mathrm{g} / \mathrm{kg} / \mathrm{min})$ & $5[0-5]$ & $3[0-5]$ & 0.316 \\
\hline Maximum dose of norepinephrine $(\mu \mathrm{g} / \mathrm{kg} / \mathrm{min})$ & $0.15[0.03-0.5]$ & $0.1[0.0-0.25]$ & 0.159 \\
\hline \multicolumn{4}{|l|}{ Postoperative outcomes } \\
\hline Mechanical ventilation (day) & $1[1-1]$ & $1[0-4]$ & 0.667 \\
\hline \multicolumn{4}{|l|}{ Major adverse cardiovascular events (n) } \\
\hline Acute coronary event & $0[0.0 \%]$ & $1[7.1 \%]$ & 1.000 \\
\hline Congestive heart failure & 2 [22.2\%] & $0[0.0 \%]$ & 0.142 \\
\hline Arrhythmia & 1 [11.1\%] & $0[0.0 \%]$ & 0.391 \\
\hline Neurological complications & 0 [0.0\%] & $0[0.0 \%]$ & - \\
\hline Early postoperative death (<30 days) & $0[0.0 \%]$ & $0[0.0 \%]$ & - \\
\hline
\end{tabular}

Data are mean [SD] or median [range]

forehead in 5 patients without CAS (35.7 \%) ( $p=$ 0.340).

Hemodynamic data at specific points during surgery are presented in Fig. 3. In both patients with and without CAS, significant within-subjects effects were detected for MAP $(p<0.001)$, cardiac index $(p<0.001)$ and CVP $(p<$ $0.001)$. Decreases in cardiac index and increases in CVP were observed at the positioning of the heart for grafting LCX and/or RCA. However, there were no significant differences in MAP $(p=0.245)$, cardiac index $(p=0.620)$, and $\operatorname{CVP}(p=0.330)$ between patients with and without CAS.

The results of multiple logistic regression analysis for cerebral desaturation during anastomosis are presented in Table 6. CAS was not associated with an increased risk of cerebral desaturation (OR 0.160, 95 \% CI 0.036$0.707, p=0.016$ ). Cardiac index $<2.01 / \mathrm{min} / \mathrm{m}^{2}$ was associated with an increased risk of cerebral desaturation (OR 3.287, 95 \% CI 2.128-5.076, $p<0.001$ ), while neither MAP $<60 \mathrm{mmHg}$ nor CVP $>10 \mathrm{mmHg}$ was associated with an independent increased risk of cerebral desaturation (OR 1.011, $95 \%$ CI 0.623-1.640, $p=0.965$ and OR 1.483, $95 \%$ CI 0.965-2.279, $p=0.072$, respectively).

\section{Discussion}

In the present study, cerebral oxygenation significantly decreased during anastomosis in both patients with and without CAS. However, the mean $\mathrm{rSO}_{2}$ value and maximum decrease in $\mathrm{rSO}_{2}$ value during anastomosis were not different between patients with and without CAS, and CAS was not a significant independent risk factor of a decrease in $\mathrm{rSO}_{2} \geq 10 \%$ from preoperative value. Moreover, a decrease in $\mathrm{rSO}_{2}$ during anastomosis was more strongly associated with a decrease in cardiac index rather than a decrease in MAP and an increase in CVP in both patients with and without CAS.

Since hemodynamic depression during cardiac displacement can lead to a decrease in cerebral oxygenation more frequently during off-pump CABG than on-pump CABG [21], patients with CAS, whose cerebral hemodynamic is impaired depending on the degree of stenosis [19], is likely to be associated with an increased risk of cerebral oxygen supply-demand mismatch to cause cerebral ischemia during off-pump CABG. However, it is unknown whether the presence of CAS can affect cerebral oxygenation in patients undergoing off-pump CABG. Consistent with previously reported studies in patients without cerebrovascular disease undergoing off-pump CABG [27, 33], $\mathrm{rSO}_{2}$ value decreased during anastomosis in both patients with and without CAS. However, there were no significant differences in mean relative change in $\mathrm{rSO}_{2}$ from preoperative value and maximum decrease in $\mathrm{rSO}_{2}$ value from preoperative value during anastomosis between patients with and without CAS, and the incidence of a critical reduction in $\mathrm{rSO}_{2}$ was not different between patients with and without CAS. Moreover, multiple logistic regression analysis demonstrated that the presence of CAS did not increase a risk 


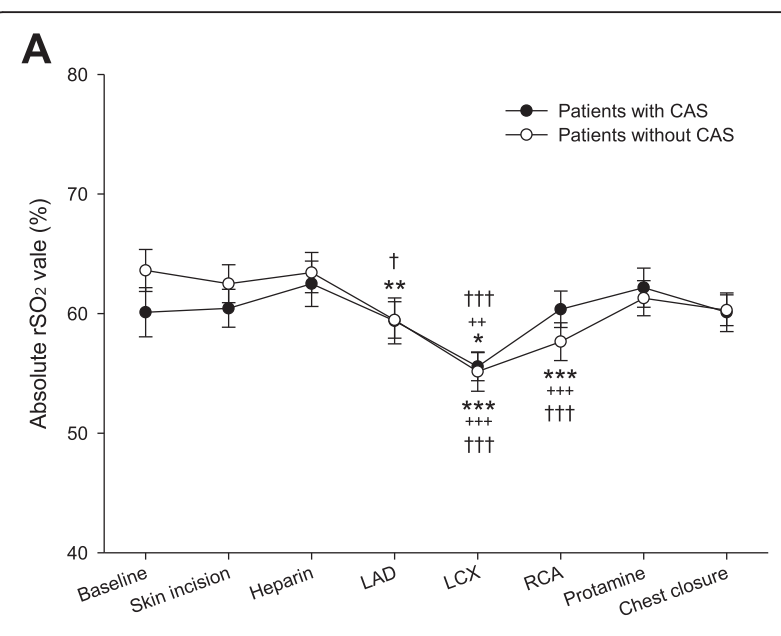

B

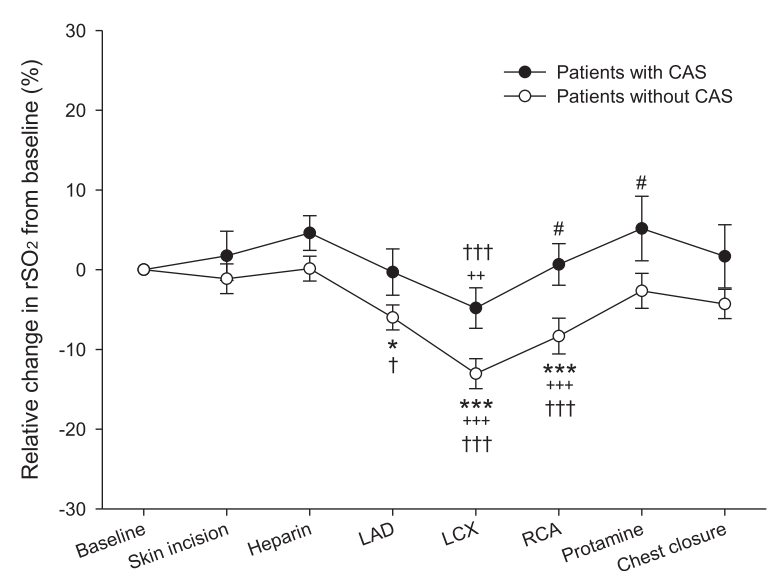

Fig. 2 Regional cerebral tissue oxygen saturation $\left(\mathrm{rSO}_{2}\right)$ in patients with and without carotid artery stenosis (CAS) (A: Absolute $\mathrm{rSO}_{2}$ value, $\mathrm{B}$ : Relative change from baseline value). The data are presented as mean (SE) and at specific points during anesthesia: before anesthesia induction (Baseline), at skin incision (Skin incision), at heparin administration (Heparin), at the beginning of grafting the left anterior descending coronary artery $(\mathrm{LAD})$, at the beginning of grafting the left circumflex coronary artery (LCX), at the beginning of grafting the right coronary artery (RCA), at protamine administration (Protamine), and at chest closure (Chest closure). ${ }^{*} p<0.05,{ }^{* *} p<0.01$, ${ }^{* * *} p<0.001$ compared with the group's Baseline. $++p<0.01$, $+++p<0.001$ compared with the group's Skin incision. $t p<0.05$, $++p<0.01,++\uparrow p<0.001$ compared with the group's Heparin administration. $\# p<0.05$ compared with patient without CAS

of a decrease in $\mathrm{rSO}_{2} \geq 10 \%$ from preoperative value, which indicates cerebral desaturation associated with cerebral dysfunction [22], and postoperative neurological complications were not identified in both patients with and without CAS. Perioperative stroke is reported to occur in 1.0-11.1\% of patients after offpump CABG [12, 13, 34-37]. However, studies showing the incidence of strokes in patients with CAS after offpump CABG are limited [35, 37]. Although a recently reported study demonstrated that CAS $\geq 50 \%$ was an independent predictor of postoperative stroke or TIA in patients receiving off-pump CABG [35], most of postoperative stroke or TIA in the study occurred several days after the surgery. This suggested that the postoperative neurological complications were related to embolus associated with postoperative hypercoagulation and atrial fibrillation rather than to intraoperative cerebral ischemia. In addition, the degree of CAS has not been shown to be associated with a risk of perioperative stroke after noncardiac surgery [38]. In the present study, although the degree of CAS varied from $50 \%$ to $100 \%$, there were no significant correlation between the degree of CAS and changes in $\mathrm{rSO}_{2}$ values during anastomosis. Considering these findings together with our results, CAS does not likely seem to be an independent risk factor of cerebral ischemia during off-pump CABG. Furthermore, in both patients with and without CAS, changes in $\mathrm{rSO}_{2}$ during anastomosis did not differ between the left and right side of the forehead, and multiple logistic regression analysis showed that bilateral CAS was not associated with an increased risk of a decrease in $\mathrm{rSO}_{2} \geq 10 \%$ from preoperative value. Although patients with bilateral CAS > $70 \%$ has been shown to be an independent risk factor of early acute cerebrovascular complications following offpump CABG [37], our results may suggest that cerebral bi-hemispheric perfusion by Willis circle was working properly in all of the study patients.

In the present study, preoperative $\mathrm{rSO}_{2}$ in patients with CAS correlated with both preoperative LVEF and MAP, while preoperative $\mathrm{rSO}_{2}$ in patients without CAS correlated with neither preoperative LVEF nor MAP. These results suggest that cerebral oxygenation in patients with CAS depended on hemodynamic status more strongly compared with patients without CAS. However, changes in $\mathrm{rSO}_{2}$ values after the induction of anesthesia did not differ between patients with and without CAS under the same anesthetic and hemodynamic management. Anesthesia-induced suppression of neural activity decreases cerebral metabolic rate of oxygen $\mathrm{CMRO}_{2}$ [39], and cerebral oxygenation during anesthetic-induced hypotension is likely to be maintained due to the neurovascular coupling between cerebral blood flow (CBF) and $\mathrm{CMRO}_{2}$ [40]. The neurovascular coupling is preserved even in patients with head injuries during propofol anesthesia [41]. Moreover, under general anesthesia, cerebral oxygenation has been shown to be maintained at preoperative level by increasing inspired oxygen fraction in both patients with and without CAS [32, 42, 43]. Thus, in both patients with and without CAS, unchanged $\mathrm{rSO}_{2}$ values after the induction of anesthesia may indicate that cerebral oxygen supply-demand mismatch was not caused by anesthetic-induced hypotension. On the contrary, in both patients with and without CAS, a decrease in cardiac index and an increase in CVP were observed during 
Table 4 Regional cerebral tissue oxygen saturation $\left(\mathrm{rSO}_{2}\right)$ during anastomosis in patients with carotid artery stenosis (CAS)

\begin{tabular}{|c|c|c|c|c|c|c|c|c|}
\hline \multirow[b]{2}{*}{ Case } & \multicolumn{4}{|l|}{ Left side } & \multicolumn{4}{|c|}{ Right side } \\
\hline & CAS (\%) & Baseline $\mathrm{rSO}_{2}(\%)$ & Mean $\mathrm{rSO}_{2}(\%)$ & Minimum $\mathrm{rSO}_{2}(\%)$ & CAS (\%) & Baseline $\mathrm{rSO}_{2}(\%)$ & Mean $\mathrm{rSO}_{2}(\%)$ & Minimum $\mathrm{rSO}_{2}(\%)$ \\
\hline 2 & 75 & 52 & 58 & 53 & 50 & 51 & 54 & 51 \\
\hline 3 & 50 & 71 & 65 & 60 & 50 & 71 & 65 & 60 \\
\hline 4 & 50 & 56 & 53 & 48 & 100 & 53 & 52 & 48 \\
\hline 5 & 50 & 65 & 52 & 45 & 50 & 72 & 59 & 54 \\
\hline 7 & 75 & 48 & 53 & 48 & 70 & 50 & 56 & 50 \\
\hline 8 & 88 & 70 & 74 & 60 & 50 & 66 & 66 & 53 \\
\hline 9 & 70 & 61 & 57 & 55 & 70 & 51 & 57 & 53 \\
\hline 10 & 90 & 52 & 62 & 59 & 0 & 57 & 65 & 62 \\
\hline 11 & 80 & 66 & 64 & 57 & 0 & 70 & 68 & 59 \\
\hline
\end{tabular}

grafting the LCX and/or RCA. Multiple logistic regression analysis showed that a decrease in cardiac index, but not an increase in CVP, was associated with an increased risk of a decrease in $\mathrm{rSO}_{2} \geq 10 \%$ from preoperative value. Several studies have demonstrated that an increase in cardiac output can cause an increase in cerebral oxygenation and perfusion [27, 43-48], and cardiac output is likely to influence CBF independent of cerebral autoregulation [27, 49]. In addition, cerebral oxygenation is shown to be largely maintained by increased extracerebral perfusion due to increased cardiac output [50]. Since decreased CBF was compensated for increased cerebral blood volume due to recruitment of collateral pathway from extracerebral artery in patients with cerebrovascular disease [19], in patients with CAS as well as those without CAS, the influence of changes in cardiac output on cerebral oxygenation is likely to be large. Meanwhile, since NIRS measures arterial, venous and capillary oxygen saturation, an increase in CVP following cardiac displacement can cause cerebral venous congestion and lead to a decrease in $\mathrm{rSO}_{2}$ value. However, patients were usually positioned in a
Trendelenburg position during grafting the LCX and/or RCA. Several studies have shown no relationship between the Trendelenburg position and a change in $\mathrm{rSO}_{2}$ value since an increase in CBF due to the Trendelenburg position increases oxygen delivery $[51,52]$. Thus, in the present study, increased CVP might not be an independent risk factor of a decrease in $\mathrm{rSO}_{2} \geq 10 \%$ from baseline value. In addition, caution is needed in $\mathrm{rSO}_{2}$ monitoring during administration of potent vasoconstrictors. Noradrenaline and phenylephrine have been demonstrated to increase internal carotid artery flow, but decrease extracerebral blood flow, resulting in decreased $\mathrm{rSO}_{2}$, without affecting CBF [50, 53-55]. The lack of relationship between a decrease in $\mathrm{rSO}_{2} \geq 10 \%$ from preoperative value and a decrease in MAP in the present study patients may reflect such effect of vasoconstrictors on $\mathrm{rSO}_{2}$ values derived from NIRS.

Limitations of the present study include its retrospective nature, small sample size for determining the significant differences in $\mathrm{rSO}_{2}$ values between patients with and without CAS, and the lack of postoperative cognitive

Table 5 Regional cerebral tissue oxygen saturation $\left(\mathrm{rSO}_{2}\right)$ during anastomosis

\begin{tabular}{|c|c|c|c|c|c|}
\hline & \multicolumn{2}{|c|}{ Patients with CAS $(n=9)$} & \multicolumn{2}{|c|}{ Patients without CAS $(n=14)$} & \multirow[t]{2}{*}{$P$ - value } \\
\hline & Left side & Right side & Left side & Right side & \\
\hline Baseline $\mathrm{rSO}_{2}(\%)$ & $60[8]$ & $60[9]$ & $63[10]$ & $65[9]$ & 0.422 \\
\hline \multicolumn{6}{|l|}{ During anastomosis } \\
\hline Mean $\mathrm{rSO}_{2}(\%)$ & $60[7]$ & $60[6]$ & $59[8]$ & $60[8]$ & 0.981 \\
\hline Mean relative change in $\mathrm{rSO}_{2}$ from baseline (\%) & $0.6[12.3]$ & $1.6[10.5]$ & $-4.8[9.2]$ & $-7.3[7.2]$ & 0.100 \\
\hline Minimum rSO $2(\%)$ & $54[6]$ & $54[5]$ & $54[8]$ & $54[8]$ & 0.977 \\
\hline Relative change in minimum rSO2 from baseline (\%) & $-9.2[12.7]$ & $-8.1[11.7]$ & $-13.5[11.3]$ & $-16.1[9.8]$ & 0.316 \\
\hline A decrease in $\mathrm{rSO}_{2} \geq 10 \%$ from baseline (min) & $0[0-75]$ & $30[0-75]$ & $23[0-195]$ & $30[0-165]$ & 0.479 \\
\hline A decrease in $\mathrm{rSO}_{2} \geq 20 \%$ from baseline (min) & $0[0-45]$ & $0[0-45]$ & $0[0-120]$ & $0[0-120]$ & 0.394 \\
\hline Absolute $\mathrm{rSO}_{2}<40 \%$ (n) & 0 & 0 & 0 & 0 & - \\
\hline
\end{tabular}

Data are mean [SD] or median [range]

CAS carotid artery stenosis 


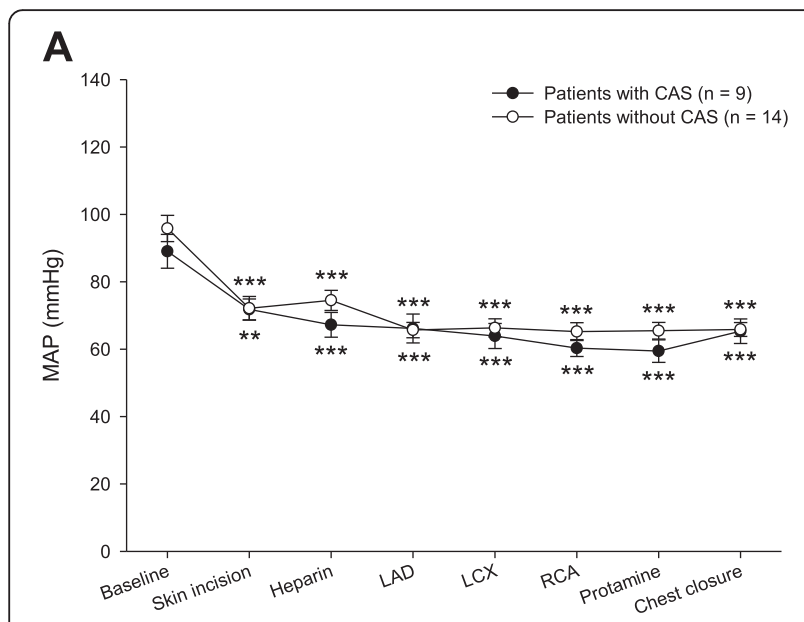

B

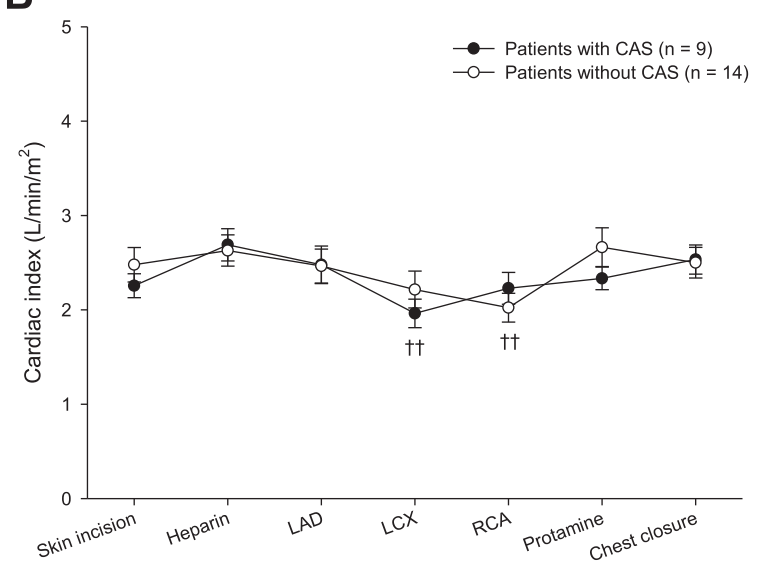

C

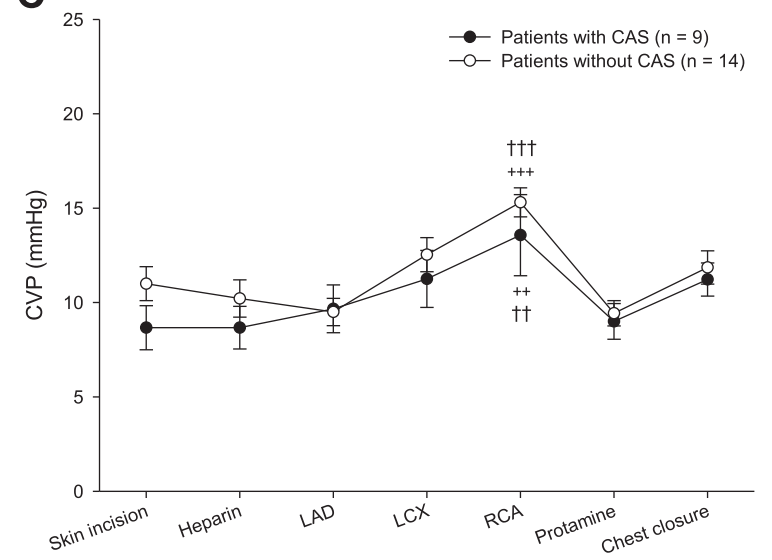

Fig. 3 Hemodynamic data in patients with and without carotid artery stenosis (CAS) (A: Mean arterial pressure (MAP), B: Cardiac index, C: Central venous pressure (CVP)). The data are presented as mean (SE) and at specific points during anesthesia: before anesthesia induction (Baseline), at skin incision (Skin incision), at heparin administration (Heparin), at the beginning of grafting the left anterior descending coronary artery $(\mathrm{LAD})$, at the beginning of grafting the left circumflex coronary artery $(\mathrm{LCX})$, at the beginning of grafting the right coronary artery (RCA), at protamine administration (Protamine), and at chest closure (Chest closure). ${ }^{* *} p<0.01,{ }^{* * *} p<0.001$ compared with the group's Baseline or Skin incision. $++p<0.01$, $+++p<0.001$ compared with the group's Skin incision. $t+p<0.01$, $+++p<0.001$ compared with the group's Heparin administration.

dysfunction assessment. Although our results suggested that CAS was not an independent risk factor of cerebral desaturation during off-pump CABG, the OR of CAS of 0.16 (95\% CI, 0.036-0.707) for cerebral desaturation also means that the risk of cerebral desaturation was lower in patients with CAS than those without CAS. All of the study patients were managed under the same anesthetic protocol, in which $\mathrm{rSO}_{2}$ target value for preventing cerebral ischemia was not determined, but surgeons and anesthesiologists might have paid more attention to hemodynamics and oxygen delivery in patients with CAS. Thus, the OR might be affected by a bias related to the retrospective nature of the study. Surgical and anesthetic management in the present study were performed by the same certified cardiovascular surgeons and anesthetists who were well trained to manage patients undergoing cardiovascular surgery, and the surgical outcomes were stable during the present study period. Although the study period extended for 5 years, the changes in surgical and anesthetic management during the period were very minor and are unlikely to impact the present results. In addition, the small differences in $\mathrm{rSO}_{2}$ values between patients with and without CAS are not likely to be of clinical importance even if the sample size were large enough to possibly detect statistically significance. In the present study, neurological complication was defined as focal neurologic deficit persisting $\geq 24 \mathrm{~h}$ and confirmed by brain CT or MRI. However, it is difficult to evaluate neurological outcomes of patients with stroke and/or TIA in anamnesis. Thus, the present study should have had to enroll only patients without neurological issues. Furthermore, since cardiac index was estimated by thermodilution technique with a pulmonary artery catheter in the present study, cardiac index in the presence of tricuspid regurgitation, such as during grafting the LCX or RCA, might be inaccurate. However, transesophageal echocardiography is not useful in such situations since the contact between the esophagus and pericardium is interrupted by air. Although $\mathrm{SvO}_{2}$, which is known to be independent of tricuspid regurgitation, is a useful 
Table 6 Multiple logistic regression analysis for a decrease in regional cerebral tissue oxygen saturation $\left(\mathrm{rSO}_{2}\right) \geq 10 \%$ from baseline value (cerebral desaturation)

\begin{tabular}{|c|c|c|c|c|c|}
\hline & OR & $95 \% \mathrm{Cl}$ & Coefficient & SE & $P$-value \\
\hline $\mathrm{MAP}<60 \mathrm{mmHg}$ & 1.011 & $0.623-1.640$ & 0.011 & 0.247 & 0.965 \\
\hline Cardiac index $<2.0 \mathrm{l} / \mathrm{min} / \mathrm{m}^{2}$ & 3.287 & $2.128-5.076$ & 1.190 & 0.222 & $<0.001$ \\
\hline CVP $>10 \mathrm{mmHg}$ & 1.483 & $0.965-2.279$ & 0.394 & 0.219 & 0.072 \\
\hline CAS & 0.160 & $0.036-0.707$ & -1.830 & 0.757 & 0.016 \\
\hline CAS side of the forehead & 0.476 & $0.040-5.670$ & -0.741 & 1.264 & 0.557 \\
\hline Bilateral CAS & 2.565 & $0.310-21.20$ & 0.942 & 1.078 & 0.382 \\
\hline Dopamine & 1.474 & $1.228-1.770$ & 0.388 & 0.093 & $<0.001$ \\
\hline Noradrenaline & 1.020 & $0.981-1.060$ & 0.020 & 0.020 & 0.315 \\
\hline
\end{tabular}

Odds ratios (ORs) with $95 \%$ confidence interval $(\mathrm{Cl})$ for cerebral desaturation during off-pump coronary artery bypass grafting for mean arterial pressure (MAP) $<60 \mathrm{mmHg}$, cardiac index $<2.0 \mathrm{l} / \mathrm{min} / \mathrm{min}^{2}$, central venous pressure (CVP) $>10 \mathrm{mmHg}$, carotid artery stenosis (CAS), CAS side of the forehead, bilateral CAS, every $1 \mu \mathrm{g} / \mathrm{kg} / \mathrm{min}$ increase in a dose of dopamine, and every $0.01 \mu \mathrm{g} / \mathrm{kg} / \mathrm{min}$ increase in a dose of noradrenaline

hemodynamic parameter for estimating cardiac output, missing $\mathrm{SvO}_{2}$ values were too much to confirm our results. Thus, the presence of tricuspid regurgitation was not assessed in the present study. However, consistent with a previously reported study [27], decreases in cardiac index was identified to be associated with decreases in $\mathrm{rSO}_{2}$ during off-pump CABG in adult patients. Further prospective studies including postoperative cognitive dysfunction assessment are warranted to confirm our findings.

\section{Conclusions}

In the present retrospective study, cerebral oxygenation significantly decreased during anastomosis in both patients with and without CAS, but CAS was not associated with an increased risk of a decrease in $\mathrm{rSO}_{2}$ value $\geq 10 \%$ from preoperative value during anastomosis. In addition, a decrease in cardiac index, but not a decrease in MAP and an increase in CVP, was associated with a decrease in $\mathrm{rSO}_{2}$ value $\geq 10 \%$ from preoperative value during anastomosis in both patients with and without CAS. In patients with CAS as well as those without CAS, maintaining cardiac output, as compared to increasing MAP, appears to be a better strategy for preventing a decrease in cerebral oxygenation during off-pump CABG.

\section{Consent}

The Institutional Ethics Committee waived the requirement for written informed consent due to the retrospective design of the study.

\footnotetext{
Abbreviations

CABG: Coronary artery bypass grafting; CPB: cardiopulmonary bypass (CPB); LVEF: Left ventricular ejection fraction; CAS: Carotid artery stenosis; NIRS: Near-infrared spectroscopy; $\mathrm{rSO}_{2}$ : Regional cerebral tissue oxygen saturation; CT: Computed tomography; $\mathrm{ETCO}_{2}$ : End-tidal carbon dioxide; BIS: Bispectral index; CVP: Central venous pressure; $\mathrm{SVO}_{2}$ : mixed venous blood oxygen saturation; MAP: Mean arterial pressure; LAD: left anterior descending coronary artery; LCX: left circumflex coronary artery; RCA: right coronary artery; MRI: magnetic resonance imaging; ANOVA: Analysis of
}

variance; OR: Odds ratio; Cl: Confidence interval; TIA: Transient ischemic attack; SPECT: Single photon emission computed tomography; $\mathrm{CMRO}_{2}$ : Cerebral metabolic rate of oxygen; $\mathrm{CBF}$ : Cerebral blood flow.

\section{Competing interests}

The authors declare that they have no competing interests.

\section{Authors' contributions}

ST designed and conducted the study, analyzed the data, and wrote the manuscript. KM helped recruit the study patients and collect the data. YT helped recruit the study patients and collect the data. MS helped design and conduct the study and analyze the data, and edited the manuscript. All authors read and approved the final manuscript.

\section{Acknowledgements}

This study was attributed to Department of Anesthesiology, Teikyo University Chiba Medical Center. Support was provided solely from department sources.

\section{Author details}

'Department of Anesthesiology, Medical Hospital of Tokyo Medical and Dental University, 1-5-45 Yushima, Bunkyo-Ku, Tokyo 113-8519, Japan. ${ }^{2}$ Department of Anesthesiology, Teikyo University Chiba Medical Center, 3426-3 Anesaki, Ichihara-City, Chiba 299-0111, Japan. ${ }^{3}$ Department of Palliative Medicine, Jikei University Graduate School of Medicine, 3-19-18 Nishi-shimbashi, Minato-Ku, Tokyo 105-8471, Japan.

Received: 12 May 2015 Accepted: 5 December 2015

Published online: 15 December 2015

\section{References}

1. McKhann GM, Grega MA, Borowicz Jr LM, Baumgarther WA, Selnes OA. Stroke and encephalopathy after cardiac surgery: an update. Stroke. 2006;37:562-71.

2. Likosky DS, Marrin CA, Caplan LR, Baribeau YR, Morton JR, Weintraub RM, et al. Determination of etiologic mechanisms of strokes secondary to coronary artery bypass graft surgery. Stroke. 2003;34:2830-4.

3. Vaage J, Jensen U, Ericsson A. Neurologic injury in cardiac surgery: aortic atherosclerosis emerges as the single most important risk factor. Scand Cardiovasc J. 2000;34:550-7.

4. Barbut D, Lo YW, Gold JP, Trifiletti RR, Yao FS, Hager DN, et al. Impact of embolization during coronary artery bypass grafting on outcome and length of stay. Ann Thorac Surg. 1997;63:998-1002.

5. Mackensen GB, Ti LK, Phillips-Bute BG, Mathew JP, Newman MF, Grocott HP, et al. Cerebral embolization during cardiac surgery: impact of aortic atheroma burden. Br J Anaesth. 2003;91:656-61.

6. Bowles BJ, Lee JD, Dang CR, Taoka SN, Johnson EW, Lau EM, et al. Coronary artery bypass performed without the use of cardiopulmonary bypass is associated with reduced cerebral microemboli and improved clinical results. Chest. 2001;119:25-30 
7. Charlesworth DC, Likosky DS, Marrin CA, Maloney CT, Quinton HB, Morton $\mathrm{JR}$, et al. Development and validation of a prediction model for strokes after coronary artery bypass grafting. Ann Thorac Surg. 2003;76:436-43.

8. Sedrakyan A, Wu AW, Parashar A, Bass EB, Treasure T. Off-pump surgery is associated with reduced occurrence of stroke and other morbidity as compared with traditional coronary artery bypass grafting: a meta-analysis of systematically reviewed trials. Stroke. 2006;37:2759-69.

9. Bakaeen FG, Vhu D, Kelly RF, Holman WL, Jessen ME, Ward HB. Perioperative outcomes after on- and off-pump coronary artery bypass grafting. Tex Heart Inst J. 2014:41:144-51.

10. Cheng DC, Bainbridge D, Martin JE, Novick RJ. Evidence-based perioperative clinical outcomes research group, Does off-pump coronary artery bypass reduce mortality, morbidity, and resourse utilization when compared with conventional coronary artery bypass? A meta-analysis of randomized trials. Anesthesiology. 2005;102:188-203.

11. Takagi H, Tanabashi T, Kawai N, Umemoto T. Off-pump surgery does not reduce stroke, compared with results of on-pump coronary artery bypass grafting: A meta analysis of randomized clinical trials. J Thorac Cardiovasc Surg. 2007;134:1059-60.

12. Lamy A, Devereaux PJ, Prabhakaran D, Taggart DP, Hu S, Paolasso E, et al. Off-pump or on-pump coronary artery bypass grafting at 30 days. N Engl J Med. 2012;366:1489-97.

13. Diegeler A, Börgermann J, Kappert U, Breuer M, Böning A, Ursulescu A, et al. Off-pump or on-pump coronary artery bypass grafting in elderly patients. $\mathrm{N}$ Engl J Med. 2013;368:1189-98.

14. Berens ES, Kouchoukos NT, Murphy SZ, Wareing TH. Preoperative carotid artery screening in elderly patients undergoing cardiac surgery. J Vasc Surg. 1992;15:313-23.

15. Huh J, Wall MJ, Soltero ER. Treatment of combined coronary and carotid artery disease. Curr Opin Cardiol. 2003;18:447-53.

16. Filsoufi F, Rahmanian PB, Castillo JG, Bronster D, Adams DH. Incidence, topography, predictors and long-term survival after stroke in patients undergoing coronary artery bypass grafting. Ann Thorac Surg. 2008:85:862-70.

17. Naylor AR, Mehta Z, Rothwell PM, Bell PR. Carotid artery disease and stroke during coronary artery bypass: a critical review of the literature. Eur J Endothorac Surg. 2002;23:283-94.

18. Gerraty RP, Gates PC, Doyle JC. Carotid artery stenosis and perioperative stroke risk in symptomatic and asymptomatic patients undergoing vascular or coronary surgery. Stroke. 1993;24:1115-8.

19. Powers WJ. Cerebral hemodynamics in ischemic cerebrovascular disease. Ann Neurol. 1991;29:231-40.

20. Li Y, Walicki D, Mathiesen C, Jenny D, Li Q, Isayev Y, et al. Strokes after cardiac surgery and relationship to carotid stenosis. Arch Neurol. 2009;66:1091-6.

21. Diephuis JC, Moons KG, Nierich AN, Bruens M, van Dijk D, Kalkman CJ. Juglar bulb desaturation during coronary artery surgery: a comparison of off-pump and on-pump procedures. Br J Anaesth. 2005;94:715-20.

22. Madsen $\mathrm{PL}$, Secher NH. Near-infrared oximetry of the brain. Prog Neurobiol. 1999;58:541-60.

23. Watzman HM, Kurth CD, Montenegro LM, Rome J, Steven JM, Nicolson SC Arterial and venous contributions to near-infrared cerebral oximetry. Anesthesiology. 2000;93:947-53.

24. Murkin JM, Adams SJ, Novick RJ, Quantz M, Bainbridge D, Iglesias I, et al. Monitoring brain oxygen saturation during coronary bypass surgery: a randomized, prospective study. Anesth Analg. 2007;104:51-8.

25. Samra SK, Dy EA, Welch K, Dorje P, Zelenock GB, Stanley JC. Evaluation of a cerebral oximeter as a monitor of cerebral ischemia during carotid endarterectomy. Anesthesiology. 2000;93:964-70.

26. Moerman AT, De Hert SG, Jacobs TF, De Wilde LF, Wouters PF. Cerebral oxygen desaturation during beach chair position. Eur J Anaesthesiol. 2012;29:82-7.

27. Moritz S, Rochon J, Völkel S, Hilker M, Hobbhahn J, Graf BM, et al. Determinants of cerebral oximetry in patients undergoing off-pump coronary artery bypass grafting: an observational study. Eur J Anaesthesiol. 2010;27:542-9.

28. Moritz S, Kasprzak P, Arlt M, Taeger K, Metz C. Accuracy of cerebral monitoring in detecting cerebral ischemia during carotid endarterectomy: a comparison of transcranial Doppler sonography, near-infrared spectroscopy, stump pressure, and somatosensory evoked potentials. Anesthesiology. 2007;107:563-9.

29. Moerman A, Vandenplas G, Bové T, Wouters PF, De Hert SG. Relation between mixed venous oxygen saturation and cerebral oxygen saturation measured by absolute and relative near-infrared spectroscopy during off-pump coronary artery bypass grafting. Br J Anaesth. 2013;110:258-65.
30. Hirofumi O, Otone E, Hiroshi I, Satosi I, Shigeo I, Yasuhiro N, et al. The effectiveness of regional cerebral oxygen saturation monitoring using near-infrared spectroscopy in carotid endarterectomy. J Clin Neurosci. 2003;10:79-83.

31. Lee TH, Marcantonio ER, Mangione CM, Thomas EJ, Polanczyk CA, Cook EF, et al. Derivation and prospective validation of a simple index for predictor of cardiac risk of major noncardiac surgery. Circulation. 1999;100:1043-9.

32. Picton P, Chambers J, Shanks A, Dorje P. The influence of inspired oxygen fraction and end-tidal carbon dioxide on post-cross-clamp cerebral oxygenation during carotid endarterectomy under general anesthesia. Anesth Analg. 2009;110:581-7.

33. Atasever B, Boer C, Speekenbrink R, Seyffert J, Goedhart P, de Mol B, et al. Cardiac displacement during off-pump coronary artery bypass grafting surgery: effect on sublingual microcirculation and cerebral oxygenation. Interact Cardiovasc Thorac Surg. 2011;13:573-7.

34. Naylor AR, Mehta Z, Rothwell PM, Bell PR. Carotid artery disease and stroke during coronary artery bypass: a critical review of the literature. Eur J Vasc Endovasc Surg. 2002;23:283-94.

35. Miyazaki S, Yoshitani K, Miura N, Irie T, Inatomi Y, Ohnishi Y. Risk factors of stroke and delirium after off-pump coronary artery bypass surgery. Interact Cardiovasc Thorac Surg. 2011:12:379-83.

36. Nishiyama K, Horiguchi M, Shizuta S, Doi T, Ehara N, Tanuguchi R, et al. Temporal pattern of strokes on-pump and off-pump coronary artery bypass graft surgery. Ann Thorac Surg. 2009;87:1839-44.

37. Wang B, Jia M, Jia S, Wan J, Zhou X, Luo Z, et al. Influencing factors for early acute cerebrovascular accidents in patients with stroke history following offpump coronary artery bypass grafting. Heart Lung Circulation. 2014;23:560-5.

38. Sonny A, Gornik HL, Yang D, Mascha EJ, Sessler DI. Lack of association between carotid artery stenosis and stroke or myocardial injury after noncardiac surgery in high-risk patients. Anesthesiology. 2014;121:922-9.

39. Michenfelder JD. The interdependency of cerebral functional and metabolic effects following massive doses of thiopental in the dog. Anesthesiology. 1974;41:231-6

40. Meng L, Gelb AW, McDonagh DL. Changes in cerebral tissue oxygen saturation during anaesthetic-induced hypotension: an interpretation based on neurovascular coupling and cerebral autoregulation. Anaesthesia. 2013;68:736-41.

41. Steiner LA, Johnston AJ, Chatfield DA, Czosnyka M, Coleman MR, Coles JP, et al. The effects of large-dose propofol on cerebrovascular pressure autoregulation in head-injured patients. Anesth Analg. 2003;97:572-6.

42. Picton $P$, Shanks A, Dorje P, Mashour GA. The influence of basic ventilation strategies on cerebral oxygenation in anesthetized patients without vascular disease. J Clin Monit Comput. 2010;24:421-5.

43. Rokamp KZ, Secher NH, Eiberg J, Lonn L, Nielsen HB. O 2 supplementation to secure the near-infrared spectroscopy determined brain and muscle oxygenation in vascular surgical patients: a presentation of 100 cases. Front Physiol. 2014;25:66.

44. Meng L, Gelb AW, Alexander BS, Cerussi AE, Tromberg BJ, Yu Z, et al. Impact of phenylephrine administration on cerebral tissue oxygen saturation and blood volume is modulated by carbon dioxide in anaesthetized patients. Br J Anaesth. 2012;108:815-22.

45. Meng L, Cannesson M, Alexander BS, Yu Z, Kain ZN, Cerussi AE, et al. Effect of phenylephrine and ephedrine bolus treatment on cerebral oxygenation in anaesthetized patients. Br J Anaesth. 2011;107:209-17.

46. Ogoh S, Sato K, Fisher JP, Seifert T, Overgaard M, Secher NH. The effect of phenylephrine on arterial and venous cerebral blood flow in healthy subjects. Clin Physiol Funct Imaging. 2011;31:445-51.

47. Nissen P, Brassard P, Jørgensen TB, Secher NH. Phenylephrine but not ephedrine reduces frontal lobe oxygenation following anesthesia-induced hypotension. Neurocrit Care. 2010;12:17-23.

48. Alexander BS, Gelb AW, Mantulin WW, Cerussi AE, Tromberg BJ, Yu Z, et al. Impact of stepwise hyperventilation on cerebral tissue oxygen saturation in anesthetized patients: a mechanistic study. Acta Anaesthesiol Scand. 2013:57:604-12.

49. Ogoh S, Brothers RM, Barnes Q, Eubank WL, Hawkins MN, Purkayastha S, et al. The effect of changes in cardiac output on middle cerebral artery mean blood velocity at rest and during exercise. J Physiol. 2005;569:697-704.

50. Sørensen H, Rasmussen P, Sato K, Persson S, Olesen ND, Nielsen HB, et al. External carotid artery flow maintains near infrared spectroscopy-determined frontal lobe oxygenation during ephedrine administration. $\mathrm{Br} J$ Anaesth. 2014;113:452-8. 
51. Harrison GR. The effect of posture on cerebral oxygenation during abdominal surgery. Anaesthesia. 2001;56:1181-4.

52. Park EY, Koo BN, Min KT, Nam SH. The effect of pneumoperitoneum in the steep Trendelenburg position on cerebral oxygenation. Acta Anaesthesiol Scand. 2009;53:895-9.

53. Davis SN, Grocott HP. Impact of extracranial contamination on regional cerebral oxygen saturation: a comparison of three cerebral oximetry technologies. Anesthesiology. 2012;116:834-40.

54. Sørensen H, Secher NH, Siebenmann C, Nielsen HB, Kohl-Bareis M, Lundby C, et al. Cutaneous vasoconstriction affects near-infrared spectroscopy determined cerebral oxygen saturation during administration of norepinephrine. Anesthesiology. 2012;117:263-70.

55. Ogoh S, Sato K, Okazaki K, Miyamoto T, Secher F, Sørensen H, et al. A decrease in spatially resolved near-infrared spectroscopy-determined frontal lobe tissue oxygenation by phenylephrine reflects reduced skin blood flow. Anesth Analg. 2014;118:823-9.

Submit your next manuscript to BioMed Central and we will help you at every step:

- We accept pre-submission inquiries

- Our selector tool helps you to find the most relevant journal

- We provide round the clock customer support

- Convenient online submission

- Thorough peer review

- Inclusion in PubMed and all major indexing services

- Maximum visibility for your research

Submit your manuscript at www.biomedcentral.com/submit
Biomed Central 